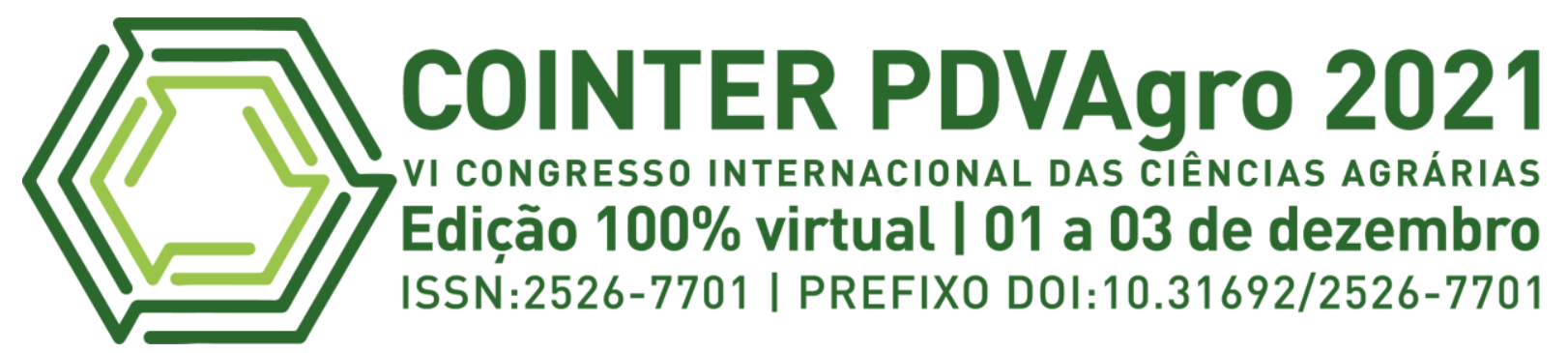

\title{
BANCO DE ALIMENTOS ONLINE: UMA PROPOSTA DE INTELIGÊNCIA PARA A CIDADE DE VITÓRIA DE SANTO ANTÃO - PE
}

\section{BANCO DE ALIMENTOS ONLINE: UNA PROPUESTA DE INTELIGENCIA PARA LA CIUDAD DE VITÓRIA DE SANTO ANTÃO - PE}

\section{ONLINE FOOD BANK: AN INTELLIGENCE PROPOSAL FOR THE CITY OF VITÓRIA DE SANTO ANTÃO - PE}

\author{
Apresentação: Comunicação Oral \\ Valéria Lopes Cruz ${ }^{1}$; Rogéria Mendes do Nascimento ${ }^{2}$; Sofia Suely Ferreira Brandão Rodrigues³; Marília Regina \\ Costa Castro Lyra ${ }^{4}$; Rejane de Moraes Rego ${ }^{5}$
}

DOI: https://doi.org/10.31692/2526-7701.VICOINTERPDVAgro.0221

\begin{abstract}
RESUMO
O presente artigo constitui-se em resultado de pesquisa desenvolvida na disciplina "Cidades Inteligentes e Sustentabilidade" do Mestrado Profissional em Gestão Ambiental do Instituto Federal de Pernambuco (MPGA/IFPE). Teve como objetivo desenvolver uma proposta de "inteligência" para uma cidade, de acordo com a temática e o universo geográfico definidos na pesquisa de mestrado do estudante. Como procedimentos metodológicos adotaram-se: pesquisa bibliográfica sobre cidades inteligentes e aplicações de tecnologias de informação e comunicação; estudos referenciais sobre iniciativas de banco de alimentos; identificação de categorias de participantes para fundamentar uma proposta de banco de alimentos online; definição do funcionamento do banco de alimentos online. A proposta de Banco de Alimentos Online para a cidade de Vitória de Santo Antão - PE contempla as diretrizes para implementação desse instrumento visando orientar o poder público. Com a criação do banco de alimentos online a cidade poderá avançar na sua inserção como cidade inteligente e sustentável, contribuindo para melhoria da qualidade de vida de seus cidadãos.
\end{abstract}

Palavras-Chave: banco de alimentos, sustentabilidade, cidades inteligentes.

\section{RESUMEN}

Este artículo es el resultado de una investigación desarrollada en la disciplina "Ciudades Inteligentes y Sostenibilidad" del Máster Profesional en Gestión Ambiental del Instituto Federal de Pernambuco (MPGA / IFPE). Se pretendía desarrollar una propuesta de "inteligencia" para una ciudad, de acuerdo con la temática y universo geográfico definido en la investigación de maestría del estudiante. Como procedimientos metodológicos se adoptaron: investigación bibliográfica sobre ciudades inteligentes y aplicaciones de tecnologías de la información y la comunicación; estudios de referencia sobre iniciativas de bancos de alimentos; identificación de categorías de participantes para apoyar una propuesta de banco de alimentos en línea; definición del funcionamiento del banco de alimentos online. La propuesta del

\footnotetext{
${ }^{1}$ Discente do Mestrado Profissional em Gestão Ambiental, IFPE, valeria.lopes@ vitoria.ifpe.edu.br

2 Docente do Mestrado Profissional em Gestão Ambiental, IFPE, rogeriamendes@ recife.ifpe.edu.br

${ }^{3}$ Docente do Mestrado Profissional em Gestão Ambiental, IFPE, sofiabrandao@ recife.ifpe.edu.br

${ }^{4}$ Docente do Mestrado Profissional em Gestão Ambiental, IFPE, marilialyra@ recife.ifpe.edu.br

${ }^{5}$ Docente do Mestrado Profissional em Gestão Ambiental, IFPE, rejanerego@ recife.ifpe.edu.br
} 
Banco de Alimentos en Línea para la ciudad de Vitória de Santo Antão - PE contempla los lineamientos para la implementación de este instrumento con el fin de orientar a las autoridades públicas. Con la creación del banco de alimentos online, la ciudad podrá avanzar en su inserción como ciudad inteligente y sostenible, contribuyendo a mejorar la calidad de vida de sus ciudadanos.

Palabras Clave: banco de alimentos, sostenibilidad, ciudades inteligentes.

\begin{abstract}
This article is the result of research developed in the discipline "Smart Cities and Sustainability" of the Professional Master's Degree in Environmental Management at the Federal Institute of Pernambuco (MPGA/IFPE). It aimed to develop a proposal of "intelligence" for a city, according to the theme and geographic universe defined in the student's master's research. As methodological procedures were adopted: bibliographic research on smart cities and applications of information and communication technologies; benchmark studies on food bank initiatives; identification of categories of participants to support an online food bank proposal; definition of the functioning of the online food bank. The Online Food Bank proposal for the city of Vitória de Santo Antão - PE contemplates the guidelines for the implementation of this instrument in order to guide the public authorities. With the creation of the online food bank, the city will be able to advance its insertion as a smart and sustainable city, contributing to improve the quality of life of its citizens.
\end{abstract}

Keywords: food bank, sustainability, smart cities.

\title{
INTRODUÇÃO
}

O aumento acelerado do processo de urbanização impõe a urgência de agilidade e diversidade de oportunidades e recursos para atender as necessidades da população, que, aliado à revolução tecnológica, projeta o surgimento do conceito de smart cities proporcionando uma atmosfera de interação dos stakeholders na busca de desenvolvimento econômico sem negligenciar a qualidade de vida.

Dotando a cidade de inteligência ao compreender as dimensões tecnológicas, ambientais, sociais e ultrapassar as barreiras físicas, o uso da tecnologia configura-se como ferramenta de governança que amplia a visão sobre todos os aspectos e as necessidades de intervenção nas questões emergentes, atuando de forma pontual e assertiva como estratégia para atenuar os impactos nas mais variadas temáticas, dada a sua versatilidade e aplicabilidade em pequena e grande escalas.

Uma importante problemática associada ao processo de urbanização é o acesso a alimentos em quantidade e qualidade suficiente, em especial devido a questões de logística e barreiras enfrentadas no escoamento, que implicam na dificuldade de circulação e aumento de custos. O Brasil é uma grande potência no cenário da produção e exportação alimentícia, com isso, os números do desperdício de alimentos também se apresentam de forma expressiva, seja devido a perdas ocorridas no decorrer da cadeia, não atingimento dos padrões comerciais, ou mesmo descarte voluntário por parte dos consumidores.

O desafio provocado por esse debate é associar o uso de recursos de tecnologia para o 
direcionamento dos produtos inutilizados no fluxo da cadeia produtiva de alimentos, numa abordagem intersetorial, identificando oferta e uma possível demanda de produtos e serviços, conectando-os de forma a mitigar os efeitos que implicam negativamente de forma direta e indireta no tripé da sustentabilidade.

A urbanização carrega consigo o estigma do crescimento desordenado resultante da busca desacertada pela ocupação dos espaços, o que reflete na necessidade de adaptações corretivas com vistas a mitigar os impactos de tais ações e prevenir mais desordem. Nesse cenário, sociedade e governo devem traçar estratégias e unir esforços para concretizar os ideais projetados seguindo os conceitos legais, bem como os morais que regem as relações sociais (BRENNER, 2018).

É importante evidenciar que mais uma consequência da concentração demográfica são as mudanças dos padrões alimentares dos indivíduos. Fatores como a logística de abastecimento e a crescente preferência por produtos industrializados e de fácil preparo/consumo deixam rastros de perdas e desperdício de alimentos em toda a cadeia produtiva, mesmo diante dos esforços dos agentes envolvidos em todo o seu percurso para reverter esse cenário. Esses fatores impactam diretamente na segurança alimentar da população que encontra diferentes tipos de barreiras no processo de construção do perfil alimentar (ASBRAN, 2019).

Infere-se da Declaração Universal dos Direitos Humanos que a alimentação é um direito de todos, sendo colocado junto a outras necessidades básicas como saúde, educação e bemestar. Quando sua concretização não se dá em quantidade, qualidade e regularidade suficientes, ou seu estabelecimento venha a comprometer o alcance de outras necessidades, têm-se um quadro de insegurança alimentar (MACHADO, 2017)

Destaca-se que a origem do desperdício está relacionada ao mau uso voluntário dos alimentos por parte dos consumidores e estabelecimentos comerciais, mas também é necessário incluir nessa cota as perdas, que se dão ao longo de toda a cadeia produtiva, seja por fatores intrínsecos à fisiologia vegetal ou ocasionados de forma involuntária como no manejo inadequado, interferência das condições climáticas ou ineficiência da embalagem, por exemplo (CAISAN, 2017; FAO, 2019).

Em oposição, o panorama mundial da fome revela que o acesso à alimentação em quantidade e qualidade suficientes ainda é um desafio, cujos dados mostram que em 2019 cerca de $8,9 \%$ da população mundial encontravam-se em situação de subnutrição. A pandemia de SARS-CoV-2 evidenciou ainda mais esse quadro, sendo estimado que mais de 100 milhões de pessoas foram adicionadas à estatísitica da fome devido aos impactos trazidos pela pandemia (FAO, 2020). 
A agenda 2030 da Organização das Nações Unidas (ONU) elenca 17 Objetivos de Desenvolvimento Sustentável (ODS), dentre eles, o ODS 2 que evoca a erradicação da fome e o estabelecimento de uma agricultura sustentável, e o ODS 12 que apela por padrões de produção e consumo sustentáveis, implicando em uma melhor gestão e preservação dos recursos naturais e, também, na redução do desperdício de alimentos (ONU, 2015).

Nesse contexto, é despertado o anseio por uma proposta de intervenção no âmbito do desperdício de alimentos, tanto em larga escala, advinda dos produtores e distribuidores, quanto aqueles executados em caráter doméstico, entusiasmando a reflexão sobre estratégias que sejam capazes de atenuar seus impactos econômicos, sociais e ambientais de forma desburocratizada e universal.

O presente artigo apresenta uma proposta de criação de Banco de Alimentos Online para a cidade de Vitória de Santo Antão, Pernambuco, Brasil, como uma resposta potencial à diminuição do desperdício de alimentos, a partir da facilitação de colaboração entre as diferentes categorias de envolvidos no processo de produção, consumo e descarte a partir da adoção de tecnologia de informação e comunicação (TIC).

\section{FUNDAMENTAÇÃO TEÓRICA}

O termo smart citiy é constantemente associado ao uso de tecnologia com o intuito de facilitar as questões de trabalho, habitação, sustentabilidade, manutenção e prevenção, ao monitoramento da infraestrutura com vistas à otimização e ao gerenciamento de recursos, à integração dos elementos de sustentabilidade e de inclusão social. Muito além da dimensão da inteligência artificial, a concepção do termo abarca a inteligência humana e coletiva, efetivando-se no conjunto de infraestruturas físicas e legislativas e devem promover a inclusão social e proteção ao meio ambiente (ALBINO et al, 2015; EREMIA et al, 2017).

Considerando que apenas da interação orgânica dos sistemas que integram a cidade, os quais economia, cidadãos, governança, mobilidade, ambiente e vida, compõe-se de fato uma cidade inteligente, ressalta-se a importância de uma visão ampla sobre todos os aspectos e a necessidade de intervenções nas questões políticas, sociais, habitacionais, de saúde e de educação no Brasil (ITU, 2014).

Diariamente são concebidos novos aplicativos (software), protótipos, plataformas que buscam a resolução de problemas comuns a indivíduos e organizações ou o aperfeiçoamento de técnicas com vistas a melhorias nos processos. Um canal para tais compartilhamentos entre os stakeholders são as bases de Tecnologias de Informação e Comunicação (TIC), que realizam a coleta dos dados em tempo real e possibilitam a universalização do acesso à informação 
(KAZUKAS, 2018).

A disponibilidade dessas informações promove o estabelecimento de uma visão holística, e torna-se também útil como suporte à tomada de decisões por parte dos gestores e estabelecimento de políticas públicas, impulsionando um melhor desempenho e eficiência governamental, proporcionando melhor monitoramento e controle das situações, enfatizando a transparência do processo e aumentando o sentimento de pertencimento dos cidadãos (GOMES, 2017).

Com o olhar voltado para o progresso mundial e a qualidade de vida, as Nações Unidas instituíram em 2015 os 17 Objetivos de Desenvolvimento Sustentável, um convite à comunidade global a unir esforços para a proteção do meio ambiente e no combate à pobreza, buscando assegurar os direitos humanos, apoiando-se nas dimensões do tripé da sustentabilidade: social, ambiental e econômica (ONU, 2015).

Enfatizando a questão da segurança alimentar, o ODS 2 apela para a adoção de práticas agrícolas resilientes e sistemas produtivos sustentáveis, impulsionando a atuação dos pequenos produtores. Além disso, o acesso a alimentos seguros de qualidade e em quantidade suficiente, erradicando a vulnerabilidade, a fome e a desnutrição também estão elencados nesse Objetivo (ONU, 2015).

De maneira complementar, o ODS 12 também busca uma gestão sustentável e o uso eficiente dos recursos naturais, postulando uma redução no desperdício de alimentos em todos os níveis de consumo, bem como ao longo de toda a cadeia produtiva. Somado a isso, propõe que seja reduzida a geração de resíduos pela adoção de práticas preventivas, redução, reciclagem ou reuso, incentivando ainda as empresas à adoção de práticas sustentáveis (ONU, 2015).

No entanto, na prática, o que se observa é um expressivo número de perdas e desperdício de alimentos em todo o mundo, cenário que implica diretamente na economia ao restringir a disponibilidade dos alimentos, induzir um aumento nos custos produtivos, e diminuição na renda do produtor. De forma complementar, o desgaste de recursos naturais atribuído à produção não aproveitada, retrata a deficiência das políticas públicas e dos sistemas produtivos (BENITEZ, 2014).

As perdas ocorridas durante a cadeia produtiva chegam a contabilizar 14\%. Apesar de um número alto, esse percentual retrata problemas involuntários, muitas vezes inevitáveis e de difícil correção, sejam gerados por desordens fisiológicas, manejo incorreto, implicações devido ao clima, embalagem inadequada e mesmo ao não atingimento dos padrões comerciais estabelecidos (FAO, 2020). 
Todavia, quando se fala em desperdício, é evidenciado o ato do descarte voluntário ocorrido no final da cadeia produtiva, realizado por parte dos consumidores e estabelecimentos comerciais devido a problemas com armazenamento, prazos de validade, aquisições excessivas e mesmo a falta de conscientização. De acordo com Porpino et al (2018), no Brasil os alimentos que alcançaram o maior nível de desperdício foram arroz, carne bovina, feijão, frango, frutas e hortaliças, nessa ordem.

A Organização das Nações Unidas para Alimentação e Agricultura (FAO) estima que em todo o mundo, 1/3 dos alimentos produzidos é desperdiçado num percentual de $30 \%$ de cereais, 40 a 50\% das raízes, frutas e hortaliças, $20 \%$ de carne e produtos lácteos e $35 \%$ de peixes. Enquanto isso, no cenário mundial, cerca de 690 milhões de pessoas, encontra-se em situação de fome, frustrando a expectativa de atendimento do ODS 2 que orienta para o combate à fome e o estabelecimento da agricultura sustentável (FAO, 2020).

Nesse cenário, estratégias têm sido traçadas com vistas a remediar tais problemáticas alinhando-as em uma única solução: destinar o excesso de alimentos que ainda se encontram em bom estado para as pessoas que necessitam. Assim, organizações não governamentais (ONGs), poder público, iniciativa privada e sociedade como um todo têm unido esforços no sentido de estabelecer esse canal de escoamento através de recursos como os bancos de alimentos, intermediando os processos de oferta e demanda (RANGEL, 2016).

Vencedor do Prêmio Nobel da paz de 2020, o Programa Mundial de Alimentos (PMA) da ONU criado em 1961 nos Estados Unidos, proposto por George McGovern, nasceu da preocupação com a vulnerabilidade social no mundo, mas também com a agricultura nacional. Assim, a proposta inicial era a compra do excedente da produção alimentícia por parte do governo americano e sua distribuição nos países em desenvolvimento, gerando assistência aos necessitados, ao tempo em que impulsionava a economia (SANTANA, 2020).

Muitas ações que visam promover um ciclo sustentável ao direcionar excedentes produtivos já se mostram bastante exitosas em todo o Brasil, a exemplo da Rede Banco de Alimentos Rio Grande do Sul, ONG Banco de Alimentos do estado de São Paulo, Programa Municipal de Combate ao desperdício e à Perda de Alimentos do estado de São Paulo, Banco de Alimentos Municipal da Prefeitura de Paracatu do estado de Minas Gerais e o Mesa Brasil SESC.

Rangel (2016) relata que a inciativa dos bancos de alimentos deu-se em 1967 em Phoenix, Arizona, nos Estados Unidos, pela organização de um grupo de voluntários que angariava junto à indústria e ao comércio os gêneros alimentícios ainda em bom estado e que seriam descartados, com o objetivo de preparar refeições para serem direcionadas a indivíduos 
em situação de vulnerabilidade. A adesão foi bastante alta, superando o potencial da equipe de preparo das refeições, sendo necessário criar um sistema de redistribuição dos itens coletados para instituições filantrópicas.

É importante destacar que no Brasil existem dois formatos de funcionamento da estrutura Banco de Alimentos, sendo introduzida em um primeiro momento como estratégia não governamental durante a década de 1990 e apenas em 2003 incorporada nas políticas públicas de Seguraça Alimentar e Nutricional (SAN), apoiado pelo Ministério do Desenvolvimento Social (MDS) por meio da proposição de editais de financiamento e implantação. Foi contabilizada em 2006 a existência de 118 bancos de alimentos no Brasil, estimando-se, em 2010, um total de 200, dos quais 67 recebiam apoio do MDS e 78 apresentavam-se vinculadas ao SESC (RANGEL, 2016)

\section{Estudos referenciais sobre Banco de Alimentos}

Os casos encontrados na literatura destacam a notoriedade do sistema de banco de alimentos e sua experiência positiva no abastecimento e distribuição de alimentos, cumprindo sua função social de minimização do desperdício, fomento da segurança alimentar e promoção da saúde. Tais exemplos descritos a seguir revelam o potencial de aplicabilidade e importância do estabelecimento dessas ações.

A Rede Banco de Alimentos do Rio Grande do Sul foi idealizada em meados de 2000, quando membros da Federação das Indústrias do Rio Grande do Sul (FIERGS) instituíram o Conselho de Cidadania do órgão, fundando o Banco de Alimentos, uma Organização da Sociedade Civil de Interesse Público com o intuito de combater a fome e o desperdício de alimentos por meio de ações de coleta, armazenamento e distribuição gratuita de alimentos de qualidade a instituições beneficentes (REDE BANCO DE ALIMENTOS, 2021).

Criada em 2007 no Estado do Rio Grande do Sul, a Rede Banco de Alimentos objetivou aumentar o alcance das atividades do Banco de Alimentos da capital do estado, Porto Alegre, e é tido como o pioneiro em território nacional. Assim, hoje conta com o número de 23 bancos associados, 100 núcleos fundados, atendendo a 34 municípios com suas ações de saúde e segurança alimentar, contabilizando em 2018 o alcance de 868.082 pessoas assistidas (REDE BANCO DE ALIMENTOS, 2021).

Suas atividades são padronizadas em todas as unidades, fundamentando-se basicamente na indicação de dia e local para coleta por parte dos doadores, seguida do armazenamento em um espaço que funciona como central de arrecadações. Na sequência, nutricionistas fazem a inspeção e direcionamento conforme o perfil de cada instituição e por fim os alimentos são 
distribuídos (REDE BANCO DE ALIMENTOS, 2021).

Para ser beneficiária de tais doações, a entidade beneficente é cadastrada no Banco de Gestão e Sustentabilidade, sendo das mais variadas estruturas como asilos, creches, associações de bairros, ONGs, entre outros, que são submetidos ainda treinamentos sobre segurança alimentar, higiene e aproveitamento integral de alimentos. Além disso, as pessoas atendidas passam periodicamente por avaliação do seu estado nutricional (REDE BANCO DE ALIMENTOS, 2021).

De maneira similar, a ONG Banco de Alimentos em São Paulo, trata-se de uma associação civil que opera na cidade de São Paulo desde 1998 recolhendo e distribuindo alimentos sem valor para indústria e comércio, porém ainda aptos para o consumo. Assim, propõe-se a criar um ciclo sustentável onde excedentes de produção são destinados ao consumo, evitando os danos ao meio ambiente pelo descarte incorreto e combatendo a insegurança alimentar, favorecendo ainda a inclusão social por meio de ações educativas (ONG BANCO DE ALIMENTOS, 2018).

Pautado na modalidade de colheita urbana, o funcionamento da sua estratégia é baseado na coleta de excedentes seguida de distribuição àqueles que necessitam, as instituições cadastradas. Em parceria com pequenas e grandes empresas do ramo alimentício e produtores rurais, é estabelecido o canal que permite a destinação de tudo aquilo que não está mais dotado de valor comercial. Assim, ao ser acionada, a ONG recolhe tais alimentos e abastece as instituições por ela assistidas (ONG BANCO DE ALIMENTOS, 2018).

Por meio do Programa Municipal de Combate ao desperdício e à Perda de Alimentos, instituído pelo Decreto No 58.862, de 19 de julho de 2019, a cidade de São Paulo promove uma visão sistêmica a respeito das perdas e desperdícios de alimentos e suas consequências para a população, economia e meio ambiente ao reconhecer o direito humano à alimentação e conscientizar produtores, distribuidores, comerciantes e consumidores e incentivar a responsabilidade compartilhada e cooperação entre os agentes envolvidos em toda a cadeia produtiva (PREFEITURA DE SÃO PAULO, 2019).

Dessa forma, objetiva um maior aproveitamento dos alimentos disponíveis ao consumo, evitando seu desperdício ao ampliar o seu uso por meio de doações, além da criação de mecanismos para conter as perdas e desperdícios, a partir de iniciativas que provoquem melhorias na cadeia produtiva e estimulem a doação seja por pesquisa, capacitação, divulgação de informações, fundação e/ou ampliação de bancos de alimentos.

Os alimentos que encontram-se fora do padrão comercial, mas atendendo aos padrões sanitários de consumo oriundos da agricultura familiar, redes varejistas, atacadistas e indústrias, 
são inspecionados e destinados a entidades assistenciais que os distribuem in natura em forma de refeição para famílias de baixa renda previamente cadastradas e submetidas a capacitações e orientações com a temática da educação alimentar e nutricional (PREFEITURA DE SÃO PAULO, 2019).

As ações são realizadas atualmente em sete equipamentos públicos de abastecimento: 3 mercados e 4 feiras livres, e os comerciantes participantes são sinalizados com um selo que os identifica como socialmente responsáveis. A destinação é feita ao Banco de Alimentos Municipal que é responsável pelo cadastramento e distribuição. Cerca de 120 mil pessoas são atendidas com alimentação, além do caráter empregatício do programa ao gerar emprego em toda a cadeia e a capacitação para o desempenho das funções inerentes a todo o processo (PREFEITURA DE SÃO PAULO, 2019).

Por sua vez, na iniciativa denominda Banco de Alimentos Municipal da Prefeitura de Paracatu em Minas Gerais a estratégia da prefeitura é arrecadar alimentos junto à agricultura familiar para a confecção de um Kit Alimentação a ser distribuído de forma gratuita para pessoas em situação de insegurança alimentar e nutricional, promovendo a nutrição e direcionando o refugo da produção. Para ser contemplado, o indivíduo deve estar inscrito no Cadastro Único do Governo Federal, ser referenciado ao Centro de Referência da Assistência Social (CRAS), inserido no Programa de Atenção Integrado à Família (PAIF) (PREDEITURA DE PARACATU, 2020).

O Serviço Social do Comércio (SESC) também atua no âmbito dos Bancos de Alimentos através do seu Programa Mesa Brasil. Produtores, comerciantes, centrais de distribuição e empresas em todo o território nacional atuam a partir da doação de alimentos, produtos de higiene pessoal e limpeza, embalagens, recursos financeiros ou seus serviços e ações voluntárias, em prol de pessoas em situação de vulnerabilidade ou vítimas de calamidade (SESC, 2020).

São desenvolvidas atividades de colheita urbana, ao resgatar e direcionar os produtos, mas também opera como banco de alimentos armazenando e disponibilizando os itens em seu espaço físico. Além disso, também são desenvolvidas ações de cunho educativo por meio de cursos, palestras e conversas nas áreas de Nutrição e Serviço Social, buscando difundir maiores esclarecimentos sobre questões alimentares e o fortalecimento da gestão das entidades (SESC, 2020).

Além do apelo que é tornar-se uma empresa socialmente responsável e publicamente citada por suas ações, o chamado para contribuir com o projeto está na contrapartida que é oferecida em forma de capacitação para os colaboradores por meio da participação nas ações 
educativas, diminuição dos custos atribuídos ao descarte evitado, isenção de ICMS, viabilização do voluntariado corporativo (SESC, 2020).

Em todo o Brasil, mais de 6000 instituições são beneficiadas pelo programa que ampara instituições de idosos, crianças, dependentes químicos, hospitais, pessoas em situação de rua, creches, que atendem os critérios de seleção são cadastradas, sendo sua permanência garantida mediante a participação nas ações e acompanhamento técnico de sua evolução. Desde 2008 o programa se dispõe também a coordenar a rede de solidariedade quando do acontecimento de desastres e catástrofes onde pessoas são expostas a situações de risco (SESC, 2020).

No Estado de Pernambuco, o SESC atua com a iniciativa desde 2002, estando presente nas cidades de Recife e Região Metropolitana, Caruaru, Garanhuns, Arcoverde e Petrolina, por intermédio das filiais instaladas em seus territórios. Durante a pandemia do COVID em 2020, com uma redução das doações convencionais, recursos arrecadados de apresentações musicais online foram convertidos em cestas básicas e distribuídos pela Caravana Solidária, inclusive em locais onde não estão presentes unidades do SESC (SESC, 2020).

Gomes (2017) destaca uma das TICs, a internet (a mais conhecida e dominada hoje) com a qual outras tecnologias se articulam, argumentando que a possibilidade de aliar a conexão em rede aos processos que estruturam o cotidiano é uma das grandes vantagens de dotar a cidade de inteligência, em benefício da melhoria da qualidade de vida e do meio ambiente, repercutindo no impulso da sua força e ampliação do seu alcance. O autor destaca seu potencial de conectar os lados envolvidos na ação, encurtando as distâncias, amenizando as burocracias, dando maior fluidez ao curso das informações.

\section{METODOLOGIA}

A pesquisa constitui-se como exploratória e de tipo bibliográfica quanto ao procedimento técnico e fontes de informação adotados (GIL, 2008), adequando-se aos condicionantes e limites impostos ao ser realizada no contexto didático da disciplina "Cidades Inteligentes e Sustentabilidade" do MPGA/IFPE.

Definiram-se como etapas os seguintes procedimentos:

1. Pesquisa bibliográfica sobre desperdício de alimentos;

2. Pesquisa bibliográfica sobre cidades inteligentes;

3. Pesquisa bibliográfica sobre aplicação de tecnologias de informação e comunicação na construção de cidades inteligentes;

4. Pesquisa bibliográfica e documental sobre segurança alimentar e sobre a cidade de Vitória de Santo Antão: dados socioeconômicos; 
5. Estudos referenciais sobre a criação de mecanismos para diminuição do desperdício de alimentos: bancos de alimentos, reaproveitamento, etc.;

6. Identificação dos potenciais agentes envolvidos no ciclo de produção comercialização - consumo - descarte de alimentos para definição das categorias de participantes da plataforma online proposta;

7. Elaboração das diretrizes para implementação da proposta de Banco de Alimentos para Vitória de Santo Antão.

Para construção das diretrizes procedeu-se à análise dos estudos referenciais, observando a estruturação e funcionamento, para incorporar tecnologia que facilite ou resolva dificuldades de comunicação e/ou colaboração entre os agentes envolvidos na cadeia de produção, comercialização, consumo e descarte de alimentos.

\section{RESULTADOS E DISCUSSÃO}

Localizada na Zona da Mata do estado de Pernambuco e distante 48km da capital Recife (Figura 01), a Cidade de Vitória de Santo Antão possui uma extensão de $372 \mathrm{~km}^{2}$ e uma população estimada pelo último censo em pouco mais de 139 mil habitantes, concentrada principalmente nas faixas etárias de 15 a 34 anos, dos quais 46,7\% possuem rendimento nominal mensal de até 1/2 salário-mínimo (IBGE, 2020).

Figura 01: Localização da cidade de Vitória de Santo Antão - PE

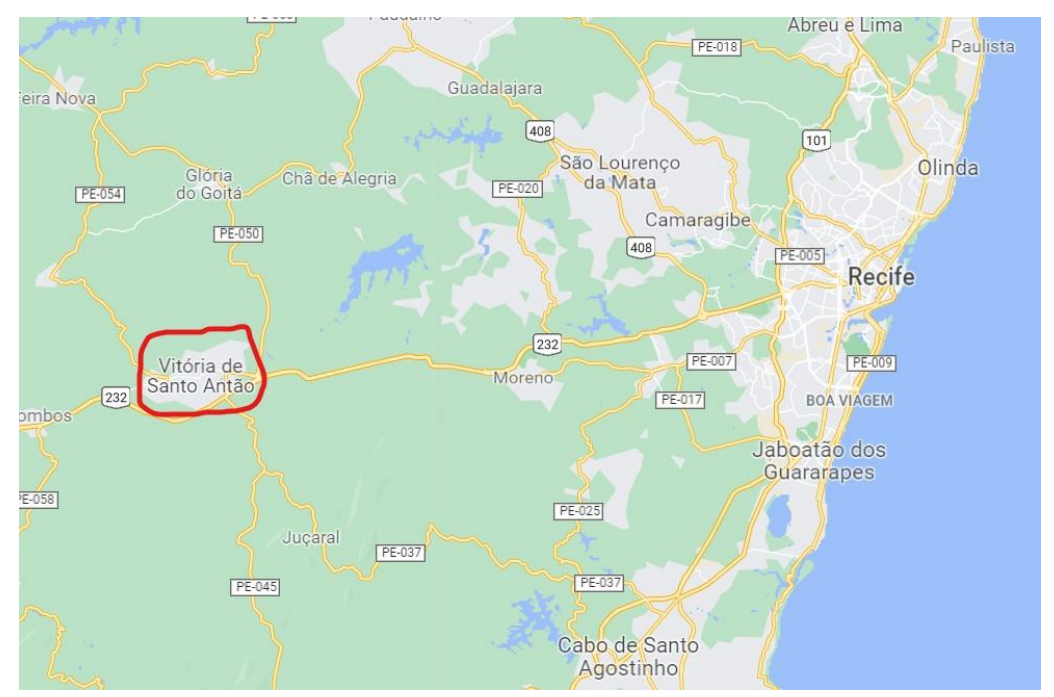

Fonte: Google Maps, 2021

A economia do município está baseada na agricultura, indústria, comércio e prestação de serviços, havendo alta produção hortifruti nos seus três principais polos (Natuba, Pirituba e Oiteiro) e cultivo de cana-de-açúcar. É sede de grandes empresas do ramo alimentício como a 
Sadia e BRF, o que destaca sua importância para o setor, mas também aguça a preocupação com a geração de excedentes produtivos e sua posterior destinação (MORAIS et al, 2011; IBGE, 2020).

O perfil agrícola do município e sua relevância como sede de variadas indústrias de alimentos, bem como a descrição do tamanho e a vulnerabilidade de sua população, foram os principais fatores para o desenvolvimento da proposta de criação de um banco de alimentos totalmente online, operando por meio de um aplicativo para celular de fácil acesso, disponibilizado para download de forma gratuita a toda a população.

\section{A proposta do Banco de Alimentos Online de Vitória de Santo Antão - PE}

Em relação à questão do desperdício de alimentos, as principais características do Banco de Alimentos Online proposto são CONEXÃO DIRETA e RAPIDEZ. O Banco não será diretamente envolvido nas transações, configurando-se como um instrumento digital gratuito colaborativo para promover a conexão direta e rápida entre os agentes envolvidos: os que contribuem com alimentos e aqueles que se beneficiarão da contribuição, observando a perecibilidade dos alimentos e a urgência de quem precisa.

O Banco de Alimentos também se constitui em instrumento educativo voltado para temática da segurança alimentar.

A participação da sociedade civil, empresas ou instituições dar-se-á a partir de três categorias:

- Doadores - de alimentos que estejam em situação sanitária adequada ao consumo;

- Beneficiados - sociedade civil organizada por meio de organizações não govenamentais, entidades beneficentes, instituições religiosas ou organizações comunitárias;

- Transportadores - oferta de formas de transferência das doações para o destino final.

- Capacitadores - oferta de cursos, treinamentos, palestras, oficinas, etc. sobre o tema;

Os agentes participantes como doadores podem ser de natureza individual ou coletiva, privada ou pública, produtores, comerciantes ou consumidores, desde que cadastrados no Banco e que registrem as informações de: tipo de alimento, condições de percibilidade e quantidade.

A categoria de beneficiados é destinada ao cadastro de ONGs, entidades beneficentes, instituições religiosas, organizações comunitárias e afins.

Já os transportadores é a categoria que se dirige às pessoas, empresas ou instituições 
que se disponham a realizar o transporte dos alimentos desde o doador até o beneficiário definido. Para tanto, o cadastro deverá informar o tipo de transporte, a capacidade e o raio de atuação, de modo que o beneficiário interessado na doação anunciada, possa acionar o transporte mais adequado.

Figura 02: Categorias de agentes do Banco de Alimentos

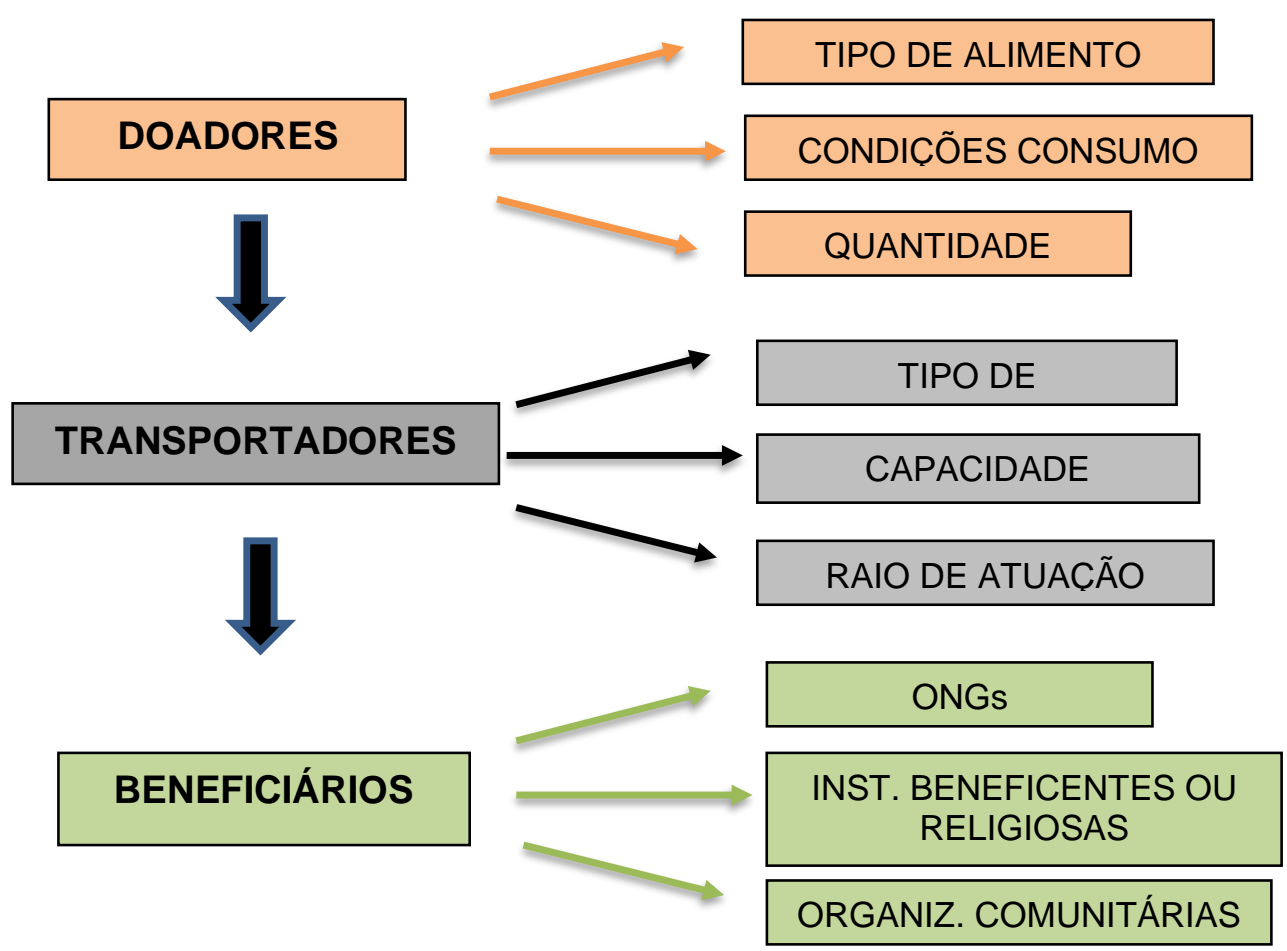

Fonte: Própria, 2021

Para a categoria capacitadores o Banco abrirá espaço para cadastro de cursos, palestras, oficinas na área de alimentos por intermédio de parcerias firmadas com instituições de ensino públicas e privadas e empreendedores, para a conscientização dos usuários. Assim, será possível aprender técnicas de preparo, armazenamento, transporte e conservação, as quais contribuirão para a quebra o ciclo do desperdício.

Como contrapartida, além da visibilidade atribuída aos atores enquanto socialmente preocupados, a ideia é a inclusão de um sistema de pontuação (mecanismo de gameficação), onde as contribuições ofertadas serão registradas, acumuladas e poderão ser revertidas em descontos em tributos, vantagens sobre os serviços municipais, ou mesmo junto a empresas por meio de programas de fidelidade ou de serviços, por exemplo.

Apesar de livre acesso, só poderão resgatar os itens usuários cadastrados. Para que sejam 
aprovados, deverão atender aos critérios de seleção e continuidade, restringindo a liberação dos donativos apenas para instituições ou ONGs de assistência a pessoas vulneráveis, indivíduos inscritos no CadÚnico do Governo Federal ou referenciados pela Secretaria de Ação Social do município.

Para um funcionamento responsável, o Banco de Alimentos Online de Vitória de Santo Antão contará também com uma política específica e de adesão obrigatória sobre os termos de uso da ferramenta, esclarecendo para ambas as partes suas obrigações e revelando punições a serem aplicadas em caso de desvios de conduta, ludibriação ou tentativa de fraude. Da mesma forma, um sistema de punições mediará os conflitos que venham a acontecer no decorrer das transações.

Para a validação da ideia, faz-se necessária uma pesquisa a respeito do contingente de produtores agrícolas, empresas do ramo alimentício e de transportes sobre sua disponibilidade para envolver-se com o projeto, com vistas a dimensionar o seu potencial para participação nas ações que compõem a estratégia, e assim avaliar a viabilidade da oferta.

Da mesma forma, a consulta ao setor de infraestrutura do município em busca de dados sobre a coleta de alimentos descartados em feiras, estabelecimentos comerciais e residências permite julgar a colaboração dessa categoria. Além disso, a realização de uma pesquisa de opinião com a sociedade civil sobre a proposta avaliará o nível potencial de engajamento com a proposta.

Será fundamental efetuar levantamentos junto à secretaria de ação social do município, lideranças comunitárias e religiosas com a finalidade de identificação do público vulnerável, a dimensão da demanda pelos serviços e do alcance que as ações precisam ter para se realizarem de forma efetiva. É imprescindível a avaliação da capacidade de utilização do recurso por todos a quem se destine, tendo em vista a tecnologia necessária para tal, buscando uma oferta equitativa do serviço.

Outro ponto crucial é estabelecer o contato com as instituições de ensino públicas e privadas e com empreendedores que trabalhem com a oferta de cursos ou tenham experiência profissional na área, para que promovam ações de ensino, pesquisa e extensão e as disponibilizem na plataforma por meio de vídeos ou vagas para intervenções em seu espaço físico.

Quanto a questão tecnológica, para implementação do Banco propõe-se recrutar as instituições de ensino e empresas do setor de TICs para que, através de seus recursos de tecnologia e pessoal capacitado, possam colaborar com o desenvolvimento e manutenção do aplicativo, empoderando-as ao despertar o sentimento de pertencimento e reduzindo custos 
associados.

Junto à Prefeitura e organizações engajadas, deve ser estudado o estabelecimento da contrapartida tributária ou certificação específica oferecida aos indivíduos e empresas, de modo que a participação se torne mais atrativa, impulsionando sua adesão, sem, no entanto, comprometer os cofres públicos ou capital empresarial.

\section{CONCLUSÕES}

O artigo apresentou a proposta para criação do Banco de Alimentos de Vitória de Santo Antão - PE, desenvolvida durante a disciplina "Cidades Inteligentes e Sustentabilidade" do Mestrado Profissional em Gestão Ambiental do IFPE.

A pesquisa realizada tornou ainda mais evidente a importância do desenvolvimento de estratégias que visem a mitigação dos impactos sociais, econômicos e ambientais gerados pelo desperdício de alimentos que ainda estão em condições sanitárias de utilização, apesar de não mais atenderem a necessidade de quem os possui (consumidor ou comerciante).

O uso de tecnologias de informação e comunicação (TIC) como instrumentos digitais que consigam desempenhar o papel de conectores entre oferta e demanda de forma rápida e eficiente passou a ser uma ferramenta imprescindível em um mundo altamente conectado. Especialmente em se tratando de gestão de itens de alta perecibilidade, visto a velocidade em que tais transações podem e devem acontecer.

Cabe a sociedade a missão de instruir-se quanto ao uso consciente dos alimentos e possibilidades de destinação correta aos seus excedentes. Cabe ainda ao poder público o estudo e a implementação de políticas que garantam a segurança alimentar da sua população, em especial àqueles mais vulneráveis. Da mesma forma, o apoio por parte do poder público a estratégias como as aqui apresentadas são fundamentais para sua implementação e sucesso.

Nesse contexto, considera-se que a proposta ora apresentada, se implementada, tem o potencial de contribuir com a diminuição do desperdício de alimentos na cidade de Vitória de Santo Antão - PE, mas, paralelamente, servir de inspiração para outras iniciativas semelhantes que busquem formas mais inteligentes de colaboração cidadã para melhoria da qualidade de vida nas cidades. 


\section{REFERÊNCIAS}

ALBINO, V.; BERARDI, U.; DANGELICO, R. M. Smart cities: definitions, dimensions, performance, and initiatives. Journal of Urban Technology. 2015. v. 22. p. 3-21, 2015.

ALVES, M. A.; DIAS, R. C.; SEIXAS, P. C. Smart cities no Brasil e em Portugal: o estado da arte. urbe, Revista Brasileira de Gestão Urbana. Curitiba, 2019. v. 11. p. 1-15, 2019.

ASBRAN. ASSOCIAÇÃO BRASILEIRA DE NUTRIÇÃO. Alimentação nutritiva precisa estar no planejamento urbano. Disponível em: https://www.asbran.org.br/noticias/alimentacao-nutritiva-precisa-estar-no-planejamentourbano. Acesso em 28 dez. 2020.

BENITEZ, R. O. Perdas e desperdícios de alimentos na América Latina e no Caribe. Disponível em: http://www.fao.org/americas/noticias/ver/pt/c/239394/. Acesso em: 30 nov. 2020.

BRENNER, N. Espaços da urbanização: o urbano a partir da teoria crítica. 1. ed. Rio de Janeiro: Letra Capital: Observatório das Metrópoles, 2018.

EREMIA, M.; TOMA, L.; SANDULEAC, M. The smart city concept in the 21st Century. ScienceDirect. Procedia Engineering. v. 181, p. 12-19, 2017.

FAO. EI estado mundial de la agricultura y la alimentación. Progresos en la lucha contra la pérdida y el desperdicio de alimentos. Roma, 2019. 198 p.

FAO. IFAD, UNICEF, WFP and WHO. The State of Food Security and Nutrition in the World 2020. Transforming food systems for affordable healthy diets. Rome, 2020. 320 p.

GIL, A. C. Métodos e técnicas de pesquisa social. $6^{\text {a }}$ ed. São Paulo: Atlas, 2008.

GOMES. M. V. Tecnologia de participação dos cidadãos nas smart cities. Lisboa, 2017. 65 p. Dissertação (Mestrado em Gestão de Informação). Instituto Superior de Estatística e Gestão da Informação, Universidade Nova de Lisboa, 2017.

IBGE. INSTITUTO BRASILEIRO DE GEOGRAFIA E ESTATÍSTICA. Vitória de Santo Antão. Disponível em: https://cidades.ibge.gov.br/brasil/pe/vitoria-de-santo-antao/. Acesso em 07 jan. 2021.

INTERNATIONAL TELECOMMUNICATION UNION - ITU. What is a smart sustainable city? Disponível em: https://itunews.itu.int/en/5215-What-is-a-smart-sustainablecity.note.aspx. Acesso em 12 jan. 2021.

KAZUKAS. G. P. Smart Cities: uso de aplicativos de tecnologia para o planejamento urbano na cidade de São Paulo. 2018. Dissertação (Mestrado em Geografia Humana). Faculdade de Filosofia, Letras e Ciências Humanas, Universidade de São Paulo, São Paulo, 2018.

LUVIELMO, M. M.; LAMAS, S. V.; Revestimentos comestíveis em frutas. Estudos Tecnológicos em Engenharia. Pelotas, 2012. v. 8. n.1. p. 8-15, 2012.

MACHADO, R. L. A. Segurança Alimentar e Nutricional e Soberania Alimentar. Disponível em: http://www4.planalto.gov.br/consea/acesso-ainformacao/institucional/conceitos. Acesso em: 12 jan. 2021. 
MORAIS, P. H. F.; ALVES, M. F. S.; SANTOS, S. T. História da Vitória de Santo Antão. Disponível em: https://www.prefeituradavitoria.pe.gov.br/site/a-cidade/. Acesso em 05 jan. 2021.

ONU. ORGANIZAÇÃO DAS NAÇÕES UNIDAS. Como as Nações Unidas apoiam os objetivos de desenvolvimento sustentável no Brasil. Disponível em: https://brasil.un.org/ptbr/sdgs. Acesso em 27 dez. 2020.

ONG BANCO DE ALIMENTOS. Disponível em: https://bancodealimentos.org.br/. Acesso em 03 jan. 2021.

PORPINO, G.; LOURENÇO, C. E.; ARAÚJO, C. M.; BASTOS, A. Intercâmbio Brasil-União Europeia sobre desperdício de alimentos: relatório final. Brasília, DF: Diálogos Setoriais União Europeia-Brasil: Embrapa. 40 p, 2018.

PREFEITURA MUNICIPAL DE PARACATU. Banco de alimentos municipal. Disponível em: http://paracatu.mg.gov.br/servico/BANCO-DE-ALIMENTOS-MUNICIPAL. Acesso em 05 jan. 2020.

PREFEITURA MUNICIPAL DE SÃO PAULO. Campanha de Combate ao Desperdício de Alimentos. Disponível em: https://www.prefeitura.sp.gov.br/cidade/secretarias/desenvolvimento/abastecimento/index.php ?p=269732. Acesso em 08 jan. 2021.

PREFEITURA MUNICIPAL DE SÃO PAULO. Decreto No 58.862, de 19 de julho de 2019. Disponível

http://diariooficial.imprensaoficial.com.br/nav_cidade/index.asp?c=1\&e=20190720\&p=1\&cli pID=d6cff1cf93f3a7b996036098ac046828. Acesso em 03 jan. 2021.

PREFEITURA MUNICIPAL DE SÃO PAULO. Programa Banco de Alimentos. Disponível em: https://bancodealimentos.org.br/. Acesso em 08 jan. 2021.

RANGEL, T. L. V. O programa banco de alimentos como instrumento de concreção do direito humano à alimentação adequada. Petrópolis: Lex Humana, 2016. v. 8. p. 120-136, 2016.

REDE DE BANCOS DE ALIMENTOS DO RIO GRANDE DO SUL. Disponível em: https://www.redebancodealimentos.org.br/Inicial. Acesso em 02 jan. 2021.

SANTANA, J. O Nobel da Paz, o Programa Mundial de Alimentos e o exemplo do Brasil no combate à fome. Disponível em: https://neai-unesp.org/o-nobel-da-paz-o-programamundial-de-alimentos-e-o-exemplo-do-brasil-no-combate-a-fome/. Acesso em 10 out. 2021.

SERVIÇO SOCIAL DO COMÉRCIO - SESC. MESA BRASIL. Disponível em: http://sesc.com.br/portal/site/mesabrasilsesc/home/. Acesso em 03 jan. 2021. 